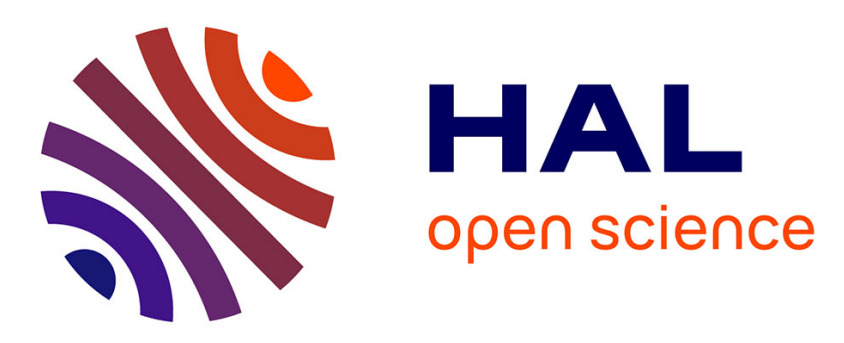

\title{
Barrier properties and hydrothermal ageing of amorphous alumina coatings applied on pharmaceutical vials
}

Pierre-Luc Etchepare, Diane Samelor, Hugues Vergnes, Brigitte Caussat, Constantin Vahlas

\section{To cite this version:}

Pierre-Luc Etchepare, Diane Samelor, Hugues Vergnes, Brigitte Caussat, Constantin Vahlas. Barrier properties and hydrothermal ageing of amorphous alumina coatings applied on pharmaceutical vials. Surface and Coatings Technology, 2021, 425, pp.127711. 10.1016/j.surfcoat.2021.127711 . hal03347223

\section{HAL Id: hal-03347223 \\ https://hal.science/hal-03347223}

Submitted on 17 Sep 2021

HAL is a multi-disciplinary open access archive for the deposit and dissemination of scientific research documents, whether they are published or not. The documents may come from teaching and research institutions in France or abroad, or from public or private research centers.
L'archive ouverte pluridisciplinaire HAL, est destinée au dépôt et à la diffusion de documents scientifiques de niveau recherche, publiés ou non, émanant des établissements d'enseignement et de recherche français ou étrangers, des laboratoires publics ou privés. 


\title{
Barrier properties and hydrothermal ageing of
}

amorphous alumina coatings applied on pharmaceutical vials.

\author{
Pierre-Luc Etchepare ${ }^{1,2}$, Diane Samelor ${ }^{1}$, Hugues Vergnes ${ }^{2}$, Brigitte Caussat $^{2}$, \\ Constantin Vahlas ${ }^{1, *}$
}

${ }^{1}$ CIRIMAT, Université de Toulouse, CNRS, INP- ENSIACET, 4, allée Emile Monso, BP44362, 31030 Toulouse Cedex 4, France.

${ }^{2}$ LGC, Université de Toulouse, CNRS, INP- ENSIACET, 4, allée Emile Monso, BP-84234, 31432 Toulouse Cedex 4, France

* Corresponding author : constantin.vahlas@ensiacet.fr

Abstract

Actual requirements of the pharmaceutics industry for reliable, safe, long term storage of biopharmaceuticals imply the use of chemically inert glass vials. This can be achieved by applying a barrier coating on their internal surface. In the present work we investigate the hydrolytic resistance of amorphous alumina coatings applied by chemical vapor deposition at the interior of soda lime glass containers. Autoclaving for $60 \mathrm{~min}$ at $121{ }^{\circ} \mathrm{C}$ and 2 bar absolute pressure of water filled such containers according to normed tests defined by the European Pharmacopeia, reveal that the concentrations of extractables obtained from the glass and released into the solution in contact, are low. The acidification of the water inside the bottle leads to the partial delamination of a $300 \mathrm{~nm}$ thick alumina coating and results in a significant release of aluminum ions. This is due to the previously identified alteration of the external part of the film. In contrast, alumina layers thinner than $20 \mathrm{~nm}$, show concentrations of 
extractables, both glass and aluminum ions, that are significantly lower than those of an uncoated bottle. This preliminary result is particularly promising. It is attributed to the transformation of the nanometric alumina coating into an aluminosilicate interdiffusion layer during the deposition process, which acts as an efficient barrier, while remaining unaffected from the interaction with the content during the shelf life of the drug.

Keywords

Amorphous alumina, aluminosilicate, chemical vapor deposition, hydrolytic resistance, glass vials, Pharmacopeia 


\section{Introduction}

Since more than ten years, developments in the pharmaceutics industry have encountered challenges regarding sustainable packaging of biopharmaceuticals [1]. Such molecules are often accompanied by excipient solutions that protect them from degradation induced from changes in $\mathrm{pH}$, oxidation and other processes [2]. However, even though pharmaceutical glass vials, the primary packaging of choice, appear chemically inert towards an aqueous phase, reactive excipient solutions can still affect the glass surface, sometimes leading to the flaking through delamination [3]. Such degradation of the functionality of the primary packaging is a longstanding problem and can result in product failures that force numerous recalls. For example, a 2007 European Medicines Agency (EMA) analysis of product quality defects noted that $6 \%$ of all product quality defects were attributed to particles, often resulting from the delamination of the superficial zone of the glass in contact with the content [4-6]. It is thus mandatory to ensure complete protection of the active molecule and excipient from the container material, a fortiori in the context of high stress in the production chain as is the case of the strong demand of vial stored vaccines against the Covid19 pandemic. To meet this requirement, and in analogy with reported sodium diffusion barrier coatings on glass [7], a solution is to apply a barrier coating on the internal surface of pharmaceutical vials that can help limit the interaction between the stored drug and the glass container, extending product shelf life and sustainability. There have been efforts by the glass manufacturers in this direction involving siliconized and silica coatings. Ditter et al. proceeded to their comparative evaluation by applying severe accelerated ageing tests [8]. The authors reported significant improvement of the resistance to delamination for the coated vials without, however, demonstrating complete inertness in the test conditions. In this context, we proposed a direct liquid injection chemical vapor deposition (DLI-CVD) process for the application of 
aluminum oxide, $\mathrm{Al}_{2} \mathrm{O}_{3}$ coatings on the internal surface of such vials $[9,10]$. Despite the risk of releasing undesirable aluminum ions in the vial content, this material solution gives promise to the formation of an aluminosilicate layer, an efficient, biocompatible chemical barrier[11], by reaction with the glass surface in analogy with previously reported CVD processes[12]. In a continuous research activity since fifteen years, we have shown that CVD alumina films processed in the temperature range between $300{ }^{\circ} \mathrm{C}$ and $650{ }^{\circ} \mathrm{C}$ are amorphous with their composition evolving with increasing the deposition temperature from that of a partial hydroxide to a stoichiometric oxide [13-15]. We reported that heat treatment of such coated vials in humid atmosphere affects the surface topography and morphology, making the film rougher and more porous [10]. The purpose of the present contribution is to complete this work by focusing on the barrier performance, illustrated by the hydrolytic resistance of the deposited alumina coatings, subjected to normed tests defined by the European and US Pharmacopeias. In a more general aspect, this combined process and material solution is used as a paradigm for the protection of the internal surface of a vial against interactions with the content.

The paper is organized as follows: we first present a synthetic description of the deposition process and we introduce the conditions of the hydrolytic resistance tests. We report and discuss the outcome of these tests, in combination with the resulting surface morphology of the coatings. We then analyze the release of alkaline cations as they were determined by plasma torch optical emission spectrometry. Finally, we investigate by X-ray photoelectron spectroscopy the diffusion of alkaline cations across the coating system prior providing concluding remarks.

2. Materials and Methods 
DLI-CVD was performed in a vertical hot-wall reactor, described in detail in [16]. The upper part of this setup is equipped with a DLI Kemstream Vapbox ${ }^{\circledR}$ system that injects in the deposition zone a $0.05 \mathrm{M}$ solution of aluminum tri-isopropoxide (ATI, 98\%, Acros Organics) in anhydrous cyclohexane $\left(99.5 \%, \mathrm{H}_{2} \mathrm{O}<10 \mathrm{ppm}\right.$, Acros Organics) [9]. The reactive gas phase is driven with 300 standard cubic centimeters per minute $(\mathrm{sccm})$ pure $\mathrm{N}_{2}(99.9999 \%$, Praxair) in a vaporization chamber that is thermally regulated at $200{ }^{\circ} \mathrm{C}$. This temperature allows the instantaneous vaporization of the solution droplets without premature decomposition of the precursor or partial vaporization of the solvent. This flow line is completed at the exit of the vaporization chamber by a $100 \mathrm{sccm}$ dilution $\mathrm{N}_{2}$ gas. The latter is preheated by heating ribbons at the highest technically possible temperature, close to $110{ }^{\circ} \mathrm{C}$. Despite the 90 degrees temperature difference between the gases mixing from the two lines, the risk of partial condensation is limited because the residence time of the gas uphill the vial is short and the hardware at this position is heated at its lower part due to the vicinity with the reactor furnace. The entire gas phase is directed to the vial through a stainless steel (SS) nozzle from the upper part of the quartz tube. A SS holder maintains the glass container in the tube axis. An inductively heated SS cylinder around the reaction chamber is thermally regulated by a control thermocouple positioned at the bottom external surface on the central axis of the container. Figure 1a presents the scheme of the setup with the white arrows schematically depicting the flow path of the reactive gas. Figure $1 \mathrm{~b}$ shows the experimentally determined temperature at various points in the vial, along its revolution axis and on its internal surface, for a $480{ }^{\circ} \mathrm{C}$ set temperature. These data were obtained with a second, independent thermocouple inserted in the vial in open reactor configuration with flowing $\mathrm{N}_{2}$. The thermal profile spans between 532 and $670{ }^{\circ} \mathrm{C}$. We have previously shown that the activation energy of the process in this temperature range is particularly low (12 kJ/mol) [17]. Consequently, there are no major variations of deposition rate along the height of the vial, 
resulting in uniform film thickness [16]. Based on appropriate process modeling [18], we demonstrated that powder-free films can be obtained in these conditions when the applied flow conditions correspond to low convective flow, low gas recirculation and highly diluted precursor supply [19], which is the case, presently. The O/Al elemental ratio of films deposited in these conditions is 1.56 ; i.e. close to that of stoichiometric alumina and their carbon content is below 1 at\% [10]. Table I resumes the operating conditions of the DLI facility and of the deposition of the alumina coatings.

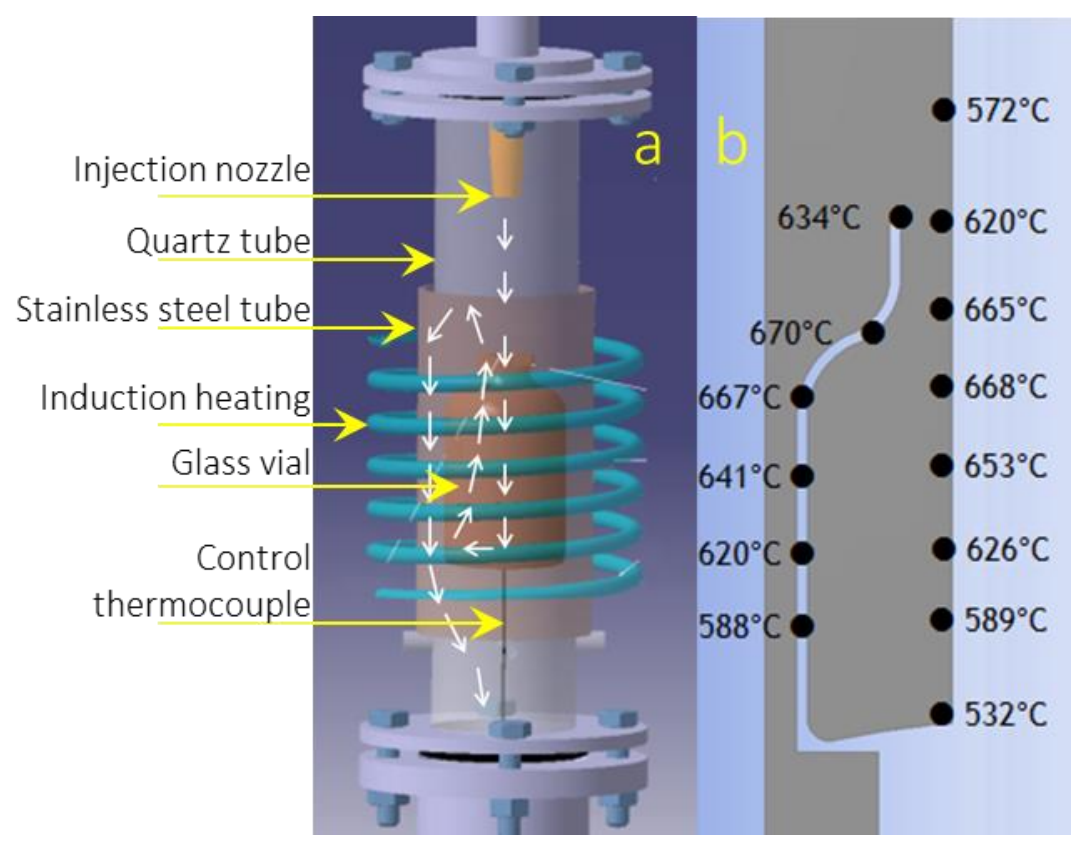

Figure 1. (a): Schematic illustration of the reactor, with the relative positions of the vial and the stainless steel cylinder with regard to the induction coil and the injector nozzle. (b): Experimentally determined temperature at various points in the vial, along its revolution axis and on its internal surface, for a $480{ }^{\circ} \mathrm{C}$ set temperature.

Table I. Direct liquid injection and alumina deposition operating conditions 


\begin{tabular}{ccc}
\cline { 2 - 3 } DLI & Injection frequency & $3 \mathrm{~Hz}$ \\
\cline { 2 - 3 } & Injection time & $3.85^{*} 10^{-3} \mathrm{~s}$ \\
\cline { 2 - 3 } & Mix N flow rate & $300 \mathrm{sccm}^{-1}$ \\
\cline { 2 - 3 } CVD & $0,7{\mathrm{~g} \cdot \mathrm{min}^{-1}}^{\text {Solution flow rate }}$ & $667 \mathrm{~Pa}(5 \mathrm{Torr})$ \\
\cline { 2 - 3 } & Deposition pressure & $753 \mathrm{~K}\left(480{ }^{\circ} \mathrm{C}\right)$ \\
\cline { 2 - 3 } & Set deposition temperature & $100 \mathrm{sccm}$ \\
\cline { 2 - 3 } & Dilution gas flow rate & $587 \mathrm{sccm}$ \\
\hline
\end{tabular}

Type III (soda-lime) glass containers (42.5 mm diameter, $73 \mathrm{~mm}$ height bottles) composed of $10 \%$ calcium oxide, $15 \%$ sodium oxide and lesser amounts of aluminum, potassium and magnesium oxides were cleaned in an ultrasonic bath with acetone and ethanol and then positioned directly in the reactor. The preheating duration of the CVD reactor once the vial is placed on the holder and the chamber closed, is $90 \mathrm{~min}$. The glass transition temperature window for this type of vials begins at ca. $600{ }^{\circ} \mathrm{C}$. However, in the present conditions, in particular for the duration of the experiment, the reported in Fig. 1 thermal profile and the gradual and slow increase and decrease of the temperature during the heating and cooling steps, the vial maintains its dimensional integrity. Eventual operation at lower temperature; i.e. in the surface reactions controlled regime, would have resulted in hydroxylated aluminum oxide films of the general formula $\mathrm{AlO}_{1+\mathrm{x}}(\mathrm{OH})_{1-2 \mathrm{x}}$ where $\mathrm{x}$ can even be zero $(\mathrm{AlOOH})[10]$. The corrosion resistance and durability of such material are low and do not meet the targeted specifications.

Alumina films of variable thickness were deposited on the internal surface of eleven such containers by varying the deposition time from 7 to $90 \mathrm{~min}$. For the lowest thicknesses, we also decreased the reactants injection flow rates, in order to maintain a controllable deposition time. The film thickness is estimated from the mass of the deposited amorphous alumina, assuming uniform deposition only on the internal walls of the vial and considering a film density of $3.4 \mathrm{g.cm}^{-3}$; i.e. that reported for such a sputtered film [20]. We previously 
demonstrated that this calculated thickness is close to that measured by scanning electron microscopy (SEM) on cross sections on the side walls of the vials [16]. However, the precise determination of the thickness variation across the lateral wall of the vial would require numerous, time consuming SEM measurements. Instead, we applied this extended control on one vial where we measured the thickness along thirteen height positions between 0 and 55 $\mathrm{mm}$, on fragmented parts of the vials. The measured mean thickness was $340 \mathrm{~nm}$ with a measured deviation of $\pm 160 \mathrm{~nm}$. Based on this evaluation protocol, the vials were coated with films of variable thickness ranging between 17 and $654 \mathrm{~nm}$.

After deposition, the vials are subjected to a hydrothermal ageing based on a titrimetric analysis defined by the European Pharmacopeia [21]. The test consists in filling uncoated and coated vials to $90 \%$ of their maximum capacity with ultra-pure water and autoclaving them for $60 \mathrm{~min}$ at $121{ }^{\circ} \mathrm{C}$ and 2 bar absolute pressure, to simulate aging during several months of storage. Filling only up to $90 \%$ allows water being in contact with the relatively homogeneous in thickness coating at the bottom and lateral walls of the vial and not with the overthickness at the neck (see Figure 11 in [19]). During the test, the alkaline ions of the glass $\left(\mathrm{Na}^{+}, \mathrm{K}^{+}, \mathrm{Ca}^{2+}, \mathrm{Mg}^{2+} \ldots\right)$ are released into the water in contact; they are hydrolyzed, resulting in the increase of $\mathrm{pH}$. After cooling, the volume $\mathrm{E}_{1}$ of the sterilized vials is collected in a test tube until a total volume of $100.0 \mathrm{~mL}$ is reached and then poured into an Erlenmeyer flask. In a flask identical to the previous one, the same volume $\mathrm{E}_{2}$ of ultra-pure water is introduced as blank. In each flask, a volume of $0.2 \mathrm{~mL}$ of methyl red solution (Carlo Erba) is added per 100 $\mathrm{mL}$ of solution. This colored indicator is red for a $\mathrm{pH}$ below 4.4 and a pale yellow for a $\mathrm{pH}$ above 6.2. Concentrated 0.01 $\mathrm{M}$ hydrochloric acid $\mathrm{HCl}$ (Chimie Plus) is used to titrate the alkali ions released from the glass into the water. In solution, $\mathrm{HCl}$ is dissociated into hydronium ion and chloride ion according to the reaction $\mathrm{HCl}_{(\mathrm{aq})}+\mathrm{H}_{2} \mathrm{O}_{(\mathrm{l})}=\mathrm{H}_{3} \mathrm{O}_{(\mathrm{aq})}^{+}+\mathrm{Cl}^{-}$. 
The acid-base titration reaction, considering $\mathrm{Na}^{+}$and $\mathrm{Cl}^{-}$ions as spectators, is: $\mathrm{H}_{3} \mathrm{O}^{+}{ }_{(\mathrm{aq})}+\mathrm{HO}^{-}$ (aq) $=\mathrm{H}_{2} \mathrm{O}_{(1)}$.

The $\mathrm{HO}^{-}$ions of the blank, corresponding to those present in the water before the autoclave cycle, are first titrated. Then, the water in contact with the vials is also titrated with the same acid solution. Here, the $\mathrm{HO}^{-}$ions present in the water before the autoclave cycle and those formed exclusively by the release of $\mathrm{Na}^{+}$are titrated. The number of released $\mathrm{Na}^{+}$moles (equal to the number of $\mathrm{HO}^{-}$moles) is therefore deduced from the difference in the volume of hydrochloric acid added to titrate the water $E_{1}$ in contact with the flasks with the volume of $\mathrm{HCl}$ to titrate the $\mathrm{E}_{2}$ blank. The results are expressed as the volume of $\mathrm{HCl}$ concentrated to $0.01 \mathrm{M}$, in milliliters (to the nearest $0.1 \mathrm{~mL}$ ). The larger this volume, the higher the concentration of released ions, the lower the hydrolytic resistance. The improvement of the hydrolytic resistance due to the application of the alumina coating on the interior surface of the vial is expressed by the barrier improvement factor (BIF), defined as the ratio of a characteristic value of the barrier property (such as the required volume of $\mathrm{HCl}$ in the hydrothermal aging test) for the bare vial to the value of this same characteristic for the coated one.

In parallel, water in contact with uncoated and coated vials after sterilization cycle is analyzed by plasma torch optical emission spectrometry (ICP-OES) with a Perkin Elmer Optima 7300 DV instrument, with the aim to quantify the concentration of alkali, alkaline earth and transition metal ions present in water. After the autoclave cycle, the bottles are shaken and in order to solubilize the formed hydroxides from the released cations, $75 \%$ vol. nitric acid is added to the contact water, in a plastic container to avoid the risk of complementary interactions with the walls. The volume of nitric acid added is between $1 \%$ vol. and $23 \%$ vol. Prior ICP-MS measurements, each extractable was calibrated allowing quantitative 
determination of the respective intensity, which is directly proportional to the concentration of the extractable.

The diffusion profile of the cations through the alumina coating was monitored by $\mathrm{X}$ ray photoelectron spectroscopy (XPS), performed on a Thermo Scientific K-Alpha instrument using monochromatic $\mathrm{Al} \mathrm{K}(1486.7 \mathrm{eV})$. The spectrometer energy was calibrated using the Au4f7/2 (83.9 $\pm 0.1 \mathrm{eV})$ and $\mathrm{Cu} 2 \mathrm{p} 3 / 2(932.7 \pm 0.1 \mathrm{eV})$ photoelectron lines. Charging compensation and neutralization were applied by using a dual beam flood gun. The probed areas were about $400 \mu \mathrm{m}$ in diameter. Surface erosion was employed using Ar ions accelerated at $2 \mathrm{kV}$, resulting in an erosion rate of about $0.08 \mathrm{~nm} \mathrm{~s}^{-1}$. Constant pass energy of $30 \mathrm{eV}$ and energy steps of $0.1 \mathrm{eV}$ were used for high resolution scans. The photoelectron peaks were analyzed by Gaussian/Lorentzian $(\mathrm{G} / \mathrm{L}=70 / 30)$ peak fitting and using a Shirley background. The atomic concentrations were determined from photoelectron peak areas using the atomic sensitivity factors reported by Scofield, taking into account the transmission function of the analyzer calculated at different pass energies from Ag3d and AgMNN peaks collected from a reference sample.

SEM and AFM were performed on coated glass fragments, obtained after carefully breaking the vial allowing for the identification of the initial position (bottom, lateral walls...) of each fragment at the vial. SEM on metalized parts was performed with a LEO 435VP instrument at $10 \mathrm{kV}$ acceleration voltage, 40 to $80 \mathrm{pA}$ probe current and $11 \mathrm{~mm}$ working distance. The surface roughness before and after the sterilization cycle, was measured by AFM in tapping mode using an Agilent 5500 instrument and the data were processed and analyzed using the Pico Image software (Agilent Technology).

3. Results and Discussion 


\section{a. Hydrolytic resistance}

Visual observation of the contained water in the vial after the autoclave test shows no difference compared with the appearance before the test, in particular no visible flakes. Figure 2 resumes the results of hydrolytic resistance of the vials as a function of the thickness of the deposited film. The upper limit value of the hydrolytic resistance for a Type I (borosilicate glass) vial and the average value of the hydrolytic resistance for a Type III vial are also reported for comparison. It is observed that, independently of the thickness of the applied film, all values of the hydrolytic resistance are below $0.45 \mathrm{~mL}$ of $\mathrm{HCl}$ at $0.01 \mathrm{M}$. The evolution of the hydrolytic resistance with increasing film thickness is not monotonous. For thin films between 39 and $113 \mathrm{~nm}$, the hydrolytic resistance varies between 0.26 and $0.43 \mathrm{~mL}$. Comparable values are obtained for the thicker films, namely $0.29 \mathrm{~mL}$ for $663 \mathrm{~nm}$. Films of intermediate thickness between 250 and $550 \mathrm{~nm}$ perform best, with hydrolytic resistance values close to $0.1 \mathrm{~mL}$. This behavior can be explained by considering that the hydrolytic resistance of a film depends on its microstructure [7, 22-26], and its thickness [22, 27]: starting from low values, the thickness increase results in the decrease of the leached ions from the vial that overcompensates an eventual increase of the concentration of $\mathrm{Al}$ ions from the coating. The stability of the hydrolytic resistance between 250 and $550 \mathrm{~nm}$ should witness either a complete compensation between the two evolving opposite trends, or an efficient barrier performance towards the glass ions and at the same time a constant release of $\mathrm{Al}$ due to unchanged microstructural characteristics of the coating. It is worth mentioning that the coating is slightly porous with nanosized cavities over the entire thickness. [10]. It is possible that this porosity is exacerbated at high thicknesses due to the growth mechanism. In such a case, the decrease of the hydrolytic resistance is solely due to the released $\mathrm{Al}$ ions from the low-in-cohesion coating. The BIF for the alumina layer compared to the average hydrolytic resistance of an uncoated Type III glass $(3.3 \mathrm{~mL}$ of $\mathrm{HCl})$ varies between 7.7 and 33 . 
Remarkably, these values also fully match the nominal performance range of more resistant Type I vials.

The performance of thin films of amorphous alumina can be compared to those of barrier coatings of a different nature such as silica, $\mathrm{SiO}_{2}$ deposited on glass vials by plasma impulse CVD (PICVD) [28, 29] and sprayed titanium oxide [30]. 150 to $190 \mathrm{~nm}$ thick $\mathrm{SiO}_{2}$ films deposited on Type I vials present a BIF between 100 and 350, while the $\mathrm{BIF}$ of $\mathrm{TiO}_{2}$ films deposited on Type I and III is 1.1 and 7, respectively. The amorphous alumina layer on a Type III glass vial therefore exhibits good barrier performance, with BIF values that are intermediate between those obtained for $\mathrm{TiO}_{2}$ and $\mathrm{SiO}_{2}$ layers.

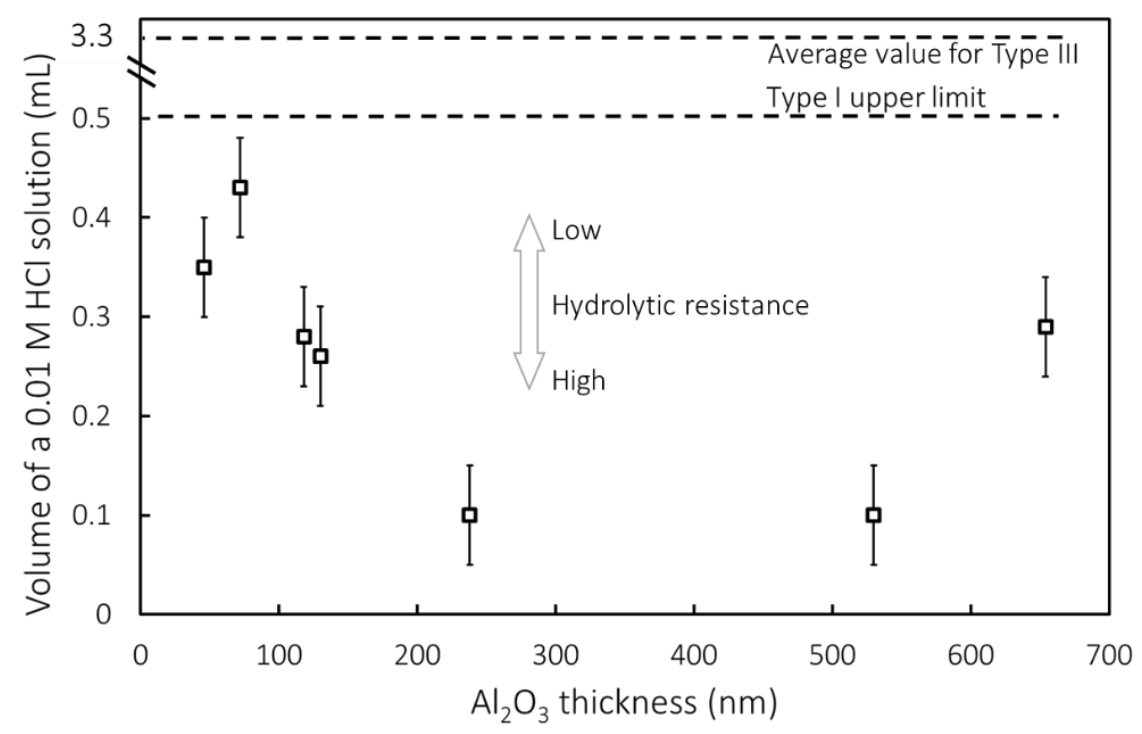

Figure 2. Evolution of the hydrolytic resistance of an alumina coated Type III vial coated with a thin film of alumina, as a function of the estimated mean thickness of the coating. The corresponding maximum volume of such solution; i.e. the minimum hydrolytic resistance of a Type I and the average value for Type III vials are also reported. 
b. Films morphology

Figure 3 illustrates the morphology and surface roughness of as processed and altered films of micrometric thickness. The former are continuous and uniformly applied on the internal surface of the vials as illustrated by the cross section of Fig. 3a. They present a smooth surface, confirmed by the AFM map of Fig. $3 b$, which reveals $1.3 \mathrm{~nm}$ RMS Sq roughness. Fig. 3c presents a cross section SEM micrograph of the coating after hydrothermal ageing. This is composed of two, superposed layers with different microstructures: an altered outer one and an inner one by the vial that is obviously unaltered. These results are comparable with those presented in [10] and imply a partial deterioration of the film subjected to the hydrolytic test with expectedly a release of aluminum ions into the contained water. Indeed, the Sq roughness of the altered coating, obtained from the AFM map of Fig. 3d is more than an order of magnitude higher than the as processed one, reaching $64.6 \mathrm{~nm}$. Skewness and kurtosis are two parameters describing the shape of the grey level histogram of images. Skewness characterizes the symmetry of the histogram; i.e. whether the darker (skewness $<0$ ) or the lighter (skewness >0) pixels are the more prominent. Kurtosis describes the flatness of the histogram, thereby discriminating the case in which there is a strong contribution of the dark and light pixels (kurtosis<3) from the images in which the vast majority of pixels is around the mean grey level (kurtosis>3). The skewness of the surface reaches -0.14 to be compared with the value of 0.40 for that of the as processed film, revealing that the hydrolysis test results in a significant emergence of an outer inter-granular porosity. This trend is confirmed from the kurtosis values, namely 2.73 for the sample that has been subjected to the hydrolytic test, to be compared to 3.00 for the as processed film. 

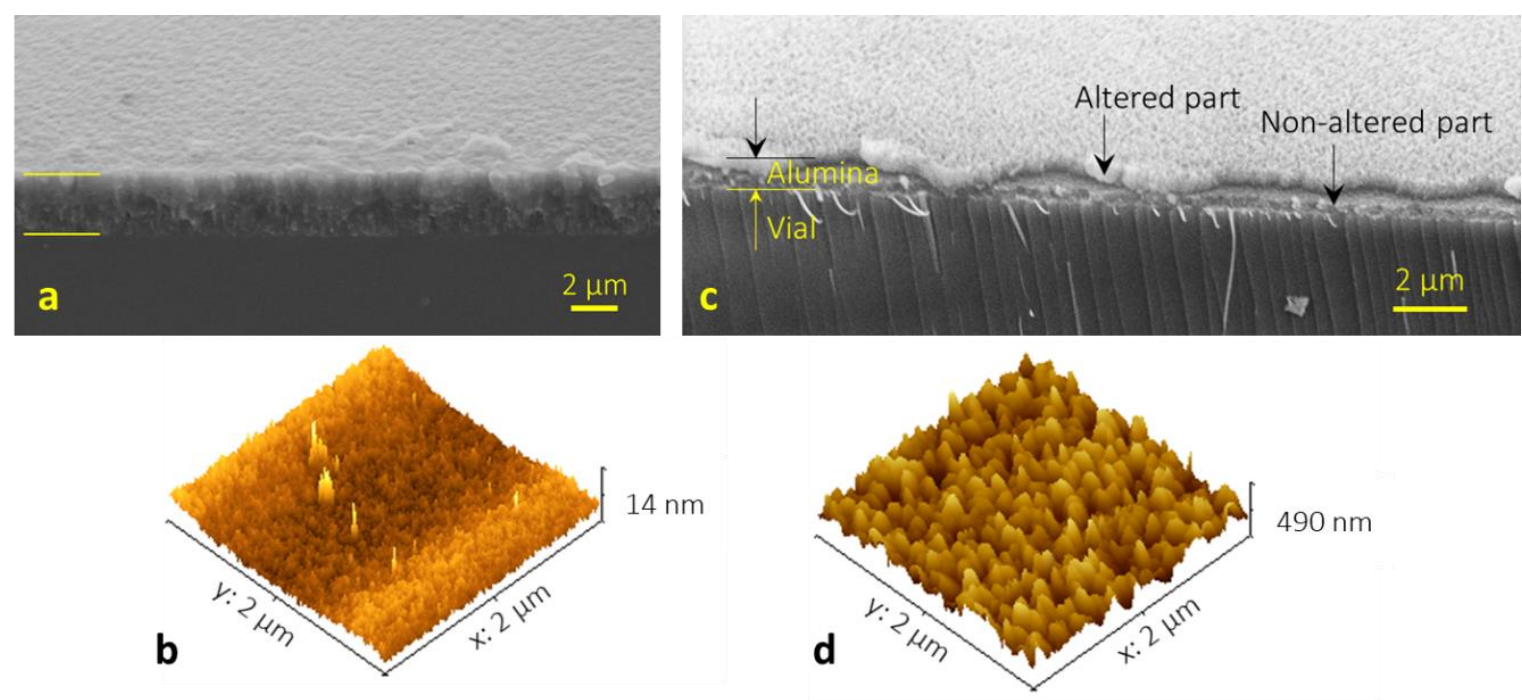

Figure 3. SEM cross section micrographs of a films deposited on the internal surface of the vial, (a) as processed, (c) after hydrothermal ageing. Corresponding AFM $2 \times 2 \mu \mathrm{m}^{2}$ maps of (b) as processed, (d) after hydrothermal ageing.

\section{c. Release of alkaline cations}

In order to understand the corrosion mechanisms of the alumina coatings during hydrothermal aging, it is important to combine hydrolytic resistance measurements with an in-depth study of the concentration of each element extracted by ICP, although such an investigation is not required by the Pharmacopoeia. The introduction of $1 \%$ vol. of nitric acid directly inside the vial and after shaking initiates the formation of flakes in the form of lamellae suspended in the contacting water. Elemental analysis by EDS reveals the presence of aluminum and oxygen atoms exclusively, indicating that these flakes are lamellae of the deposited alumina films. The question arises as to whether the formation of these flakes is initiated during the aging process in the autoclave as a consequence of the altered external pat of the coating, or if it is solely due to the action of nitric acid. For this, a comparative insight in the concentrations of extractables by ICP is carried out on acidified solutions in contact with the inner surface of the vials. Two configurations are of interest: first, the determination of ions concentration in 
the contained water of autoclaved, as-received vial. Then, the same determination for an autoclaved vial coated with a $42 \mathrm{~nm}$ thick alumina film. The total volume fraction of nitric acid added is $23 \%$ vol. In a preliminary step, it was verified that the volume of the added nitric acid does not have a significant influence on the concentrations of measured extractables. The histogram of Figure 4(a) presents the results of ICP measurements of the concentration of extractables in contacting water for the two configurations tested.
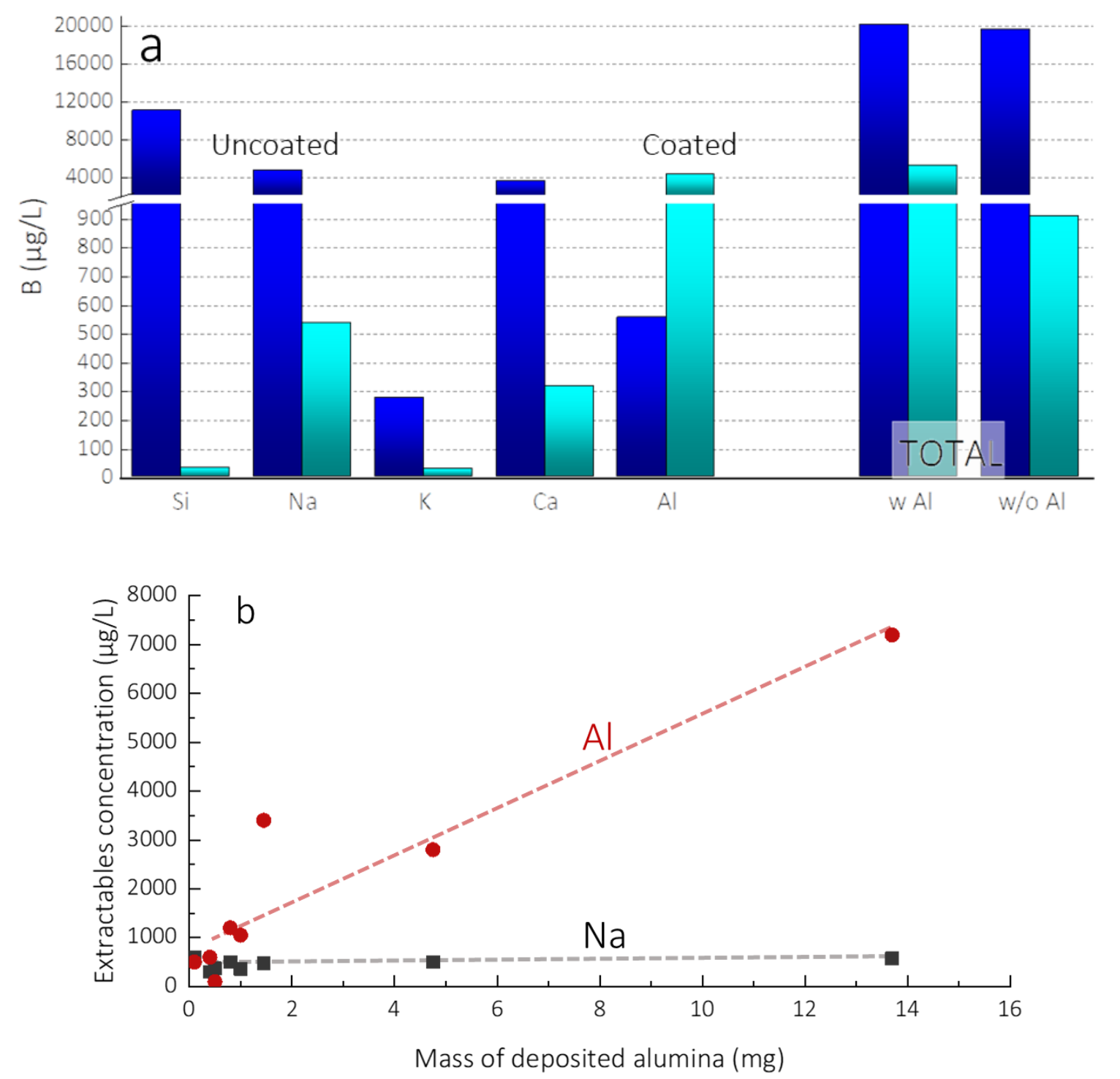

Figure 4. (a) ICP determined concentration of extractables after contact with the inside surface of an uncoated (blue) vial and a coated (cyan) one with a $42 \mathrm{~nm}$ thick alumina film. 
The last two sets of columns correspond to the total extractables with and without considering $\mathrm{Al}$ ions. (b) Evolution, as a function of the mass of the deposited alumina film, of the concentration of two extractable cations, $\mathrm{Al}$ and $\mathrm{Na}$, representative elements of the coating and the vial, respectively.

The measured concentrations of alkali, alkaline earth and silicon extracted from the inside surface of the coated container is systematically lower than those of the uncoated one. The gain is one order of magnitude for $\mathrm{Na}, \mathrm{K}$ and $\mathrm{Ca}$, and even almost three orders of magnitude for Si. The total concentration of extractables from the coated vial without taking into account the concentration of aluminum ions, namely $971 \mu \mathrm{g} / \mathrm{L}$, is 20 times lower than that for an uncoated one $(19,510 \mu \mathrm{g} / \mathrm{L})$. The concentration of $\mathrm{Al}$ ions from the coated vial is very high $(4,273 \mu \mathrm{g} / \mathrm{L})$, almost 8 times more than that of the uncoated Type III glass vial $(554 \mu \mathrm{g} / \mathrm{L})$. We attribute the high concentration of the released $\mathrm{Al}$ ions from the surface of the vial after the autoclave cycle to the fragile external part of the coating shown in Figure 3c, which is partially or totally delaminated upon interaction with the nitric acid. Indeed, $\mathrm{HNO}_{3}$ hydrolyzes the superficial alumina that is already weakened due to the hydrothermal aging and breaks the remaining - $\mathrm{O}-\mathrm{Al}-\mathrm{O}-$ bonds until the layer is delaminated. Despite this partial embrittlement, the remaining unaffected part of the coating still presents a good barrier performance against the release of alkalis, alkaline earth metals and Si from the vial. This scenario is verified by plotting, as a function of the mass of the deposited alumina film, the concentration of two extractable cations, $\mathrm{Al}$ and $\mathrm{Na}$, representative elements of the coating and the vial, respectively. The mass of the alumina is directly related to the thickness of the deposited film; hence, Figure 4(b) roughly illustrates the evolution of the concentration of the two extractables a function of the thickness of the alumina coating. It is worth recalling that the release of $\mathrm{Al}^{3+}$ and $\mathrm{Na}^{+}$ions from the uncoated vial is shown in Figure 4(a) to be 550 and 
$4500 \mu \mathrm{g} / \mathrm{L}$, respectively. A linear increase of the released $\mathrm{Al}^{3+}$ ions is observed with increasing the mass of the deposited alumina. The increase is significant, passing from 1000 $\mu \mathrm{g} / \mathrm{L}$ to more than $7000 \mu \mathrm{g} / \mathrm{L}$ when the mass of the deposited material is increased from 1 to $14 \mathrm{mg}$. This result indicates that the exchange surface increases with increasing the thickness of the film, probably due to the microporous structure of the latter, as is illustrated in Figure 3a. That the observed linearity is not valid at very low deposited mass. Indeed, the first three points of the diagram corresponding to less than $1 \mathrm{mg}$ deposited alumina are all positioned below the prevailing linear trend. This result indicates a stronger bonding of the $\mathrm{Al}$ atoms in the very first part of the coating, attributed to the creation of an interdiffusion zone with the substrate, as it will be shown and further commented later. Despite the obvious degradation of the external part of the coating, Figure 4(b) reveals that the concentration of $\mathrm{Na}+$ ions remains unchanged to a significantly low level of ca. $500 \mu \mathrm{g} / \mathrm{L}$ for all coating thicknesses investigated. This result validates the excellent barrier performance of the coating.

Additional measurements of extractable concentrations are carried out in order to double check whether the alumina layer is totally or partially delaminated, both in its thickness and in its extent all over the covered surface, after a first cycle in the autoclave and acidification inside the vial, which results in the formation of flakes. A vial coated with an alumina film of $383 \mathrm{~nm}$ mean thickness undergoes a first cycle in an autoclave. The water in contact is acidified by adding directly into the bottle $1 \%$ vol. nitric acid, responsible for the formation of flakes. An ICP analysis is carried out on the solution in contact and the extractable concentrations are illustrated by the histogram of Figure 5. The bottle is then emptied, rinsed three times with ultra-pure water and undergoes a second cycle in the autoclave. The water in contact is acidified directly in the bottle with $1 \%$ vol. nitric acid. The flakes form again and the extractable concentrations are measured and reported in Figure 5. 
The concentrations of alkaline, alkaline earth and silicon extractables from glass are low after the first $(789 \mu \mathrm{g} / \mathrm{L})$ and the second cycles $(283 \mu \mathrm{g} / \mathrm{L})$ in the autoclave. However, the concentration of silicon and alkaline earth $\left(\mathrm{Ca}^{2+}\right)$ ions increases while that of alkaline $\left(\mathrm{Na}^{+}\right.$, $\mathrm{K}^{+}$) ions decreases after the second cycle. The concentration of the released $\mathrm{Al}^{3+}$ ion is important after the first hydrothermal aging but it significantly decreases after the second one (7,244 and 1,244 $\mu \mathrm{g} / \mathrm{L}$, respectively). These results again confirm the barrier performance of the alumina coating system against the release of alkalis, alkaline earth metals and $\mathrm{Si}$, after two cycles in autoclave and acidification in the bottle. In agreement with the morphology observed in Figure 3b, delamination in the form of flakes during acidification after the first autoclave cycle is only superficial since the barrier performance of the layer is still present after the second autoclave cycle.

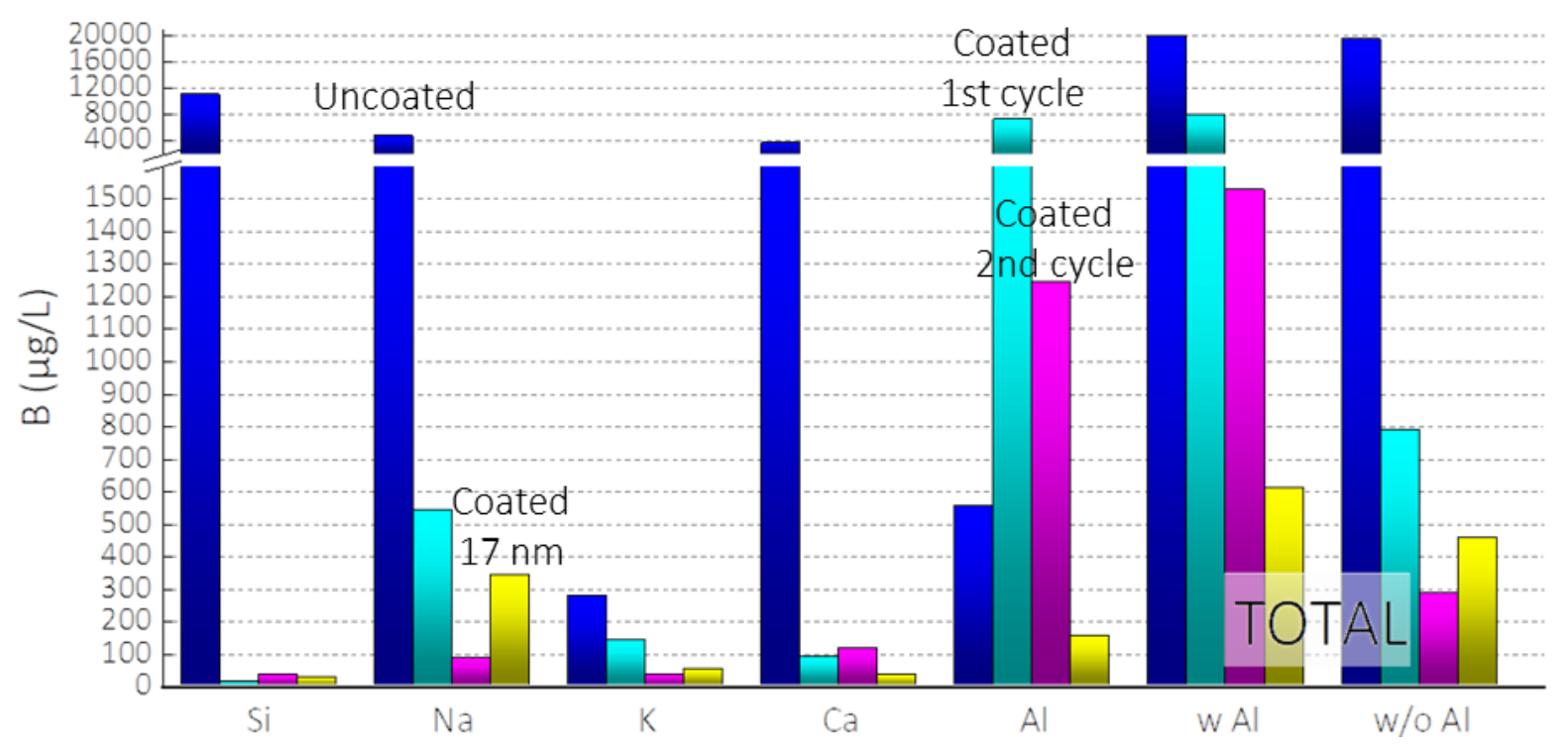

Figure 5. Concentrations of extractables from four vials: uncoated, coated with a $383 \mathrm{~nm}$ thick alumina coating after one and after two autoclave cycles, and coated with a 17 nm thick alumina film after one autoclave cycle. The last two sets of columns correspond to the total extractables with and without considering $\mathrm{Al}$ ions. 
Another vial, coated with a very thin alumina layer, the average thickness of which is estimated to be $17 \mathrm{~nm}$ was also subjected to an autoclave cycle. No flakes form in the water in contact after acidification and shaking of the bottle. The measured concentrations of alkali, alkaline earth, silicon and aluminum ions, are reported in Figure 5. The total is low (610 $\mu \mathrm{g} / \mathrm{L})$, namely 33 times lower than those of an uncoated vial $(20,090 \mu \mathrm{g} / \mathrm{L})$. The concentration of extracted sodium $(340 \mu \mathrm{g} / \mathrm{L})$ is also 1.5 times lower than that for a vial coated with a thicker film $(538 \mu \mathrm{g} / \mathrm{L})$. A remarkable result is that the concentration of extracted aluminum $(154 \mu \mathrm{g} / \mathrm{L})$ is more than 3 times lower than that of the uncoated vial. Such thin alumina layer perfectly fits the target property of efficient inert barrier film. These results are in agreement with those reported by Finley et al. [25], following which of $\mathrm{ZrO}_{2}, \mathrm{TiO}_{2}$ and zinc-tin oxide films of about ten nanometers show good performance as an alkali diffusion barrier.

As previously noticed, for coatings of thickness higher than $40 \mathrm{~nm}$, the release of aluminum ions is particularly important when the nitric acid is introduced into the vial. The concentration of $\mathrm{Al}^{3+}$ ions released into solution is higher for the coated vials than for the bare vial and it was shown that it depends on the thickness of the layer. The concentration of alkaline and alkaline earth ions released into solution is systematically lower for the coated than for the bare vial. In particular, the barrier film decreases by 8 to 13 times the concentration of the released $\mathrm{Na}^{+}$ions. These results can be correlated with measurements of hydrolytic resistance (Figure 2). It is confirmed that the coating acts as a diffusion barrier to the alkali and alkaline earth ions of the glass. After two autoclave cycles and successive acidifications, the barrier performance is still observed. However, the concentrations of the released alkaline ions, although very low, are not zero. This may mean that the layer locally contains defects (breaking up or delamination of the film) by which the ions are extracted or, alternatively, that there is still a moderate diffusion of the alkaline cations through the layer. 
This hypothesis is realistic taking into account the more porous and columnar microstructure, and the rougher surface of the alumina films deposited by DLI of ATI [10] than those deposited by sublimation of the latter [31]. Thin films of less than $20 \mathrm{~nm}$ thick alumina films appear promising in view of the low concentrations of extractables from glass and aluminum ions, all significantly lower than those of an uncoated bottle.

d. Diffusion of alkaline cations across the coating system

In addition to the determination of pure barrier performance of the coating through titrimetry and ICP, it is useful to investigate the diffusion of alkaline ions in depth, from the surface in contact with the solution towards the interface with the glass and down to the depleted, due to the extraction of alkaline ions, superficial part of the glass container. For this purpose, the concentrations of the main atomic elements present in the glass and in the film $(\mathrm{O}, \mathrm{Si}, \mathrm{Al}, \mathrm{Ca}$, $\mathrm{Mg}, \mathrm{C}$ ) are measured by XPS for two similar vials, both coated with a ca. $300 \mathrm{~nm}$ thick alumina film deposited in the same conditions. One of them is analyzed as processed, the other after being subjected to the autoclave cycle. Elemental analysis is performed for different depths of the alumina layer and the "semi-infinite" volume of the glass, the surface material being sputtered by ion bombardment between each analysis. This results in concentration profiles for each element are presented in Figure 6. 


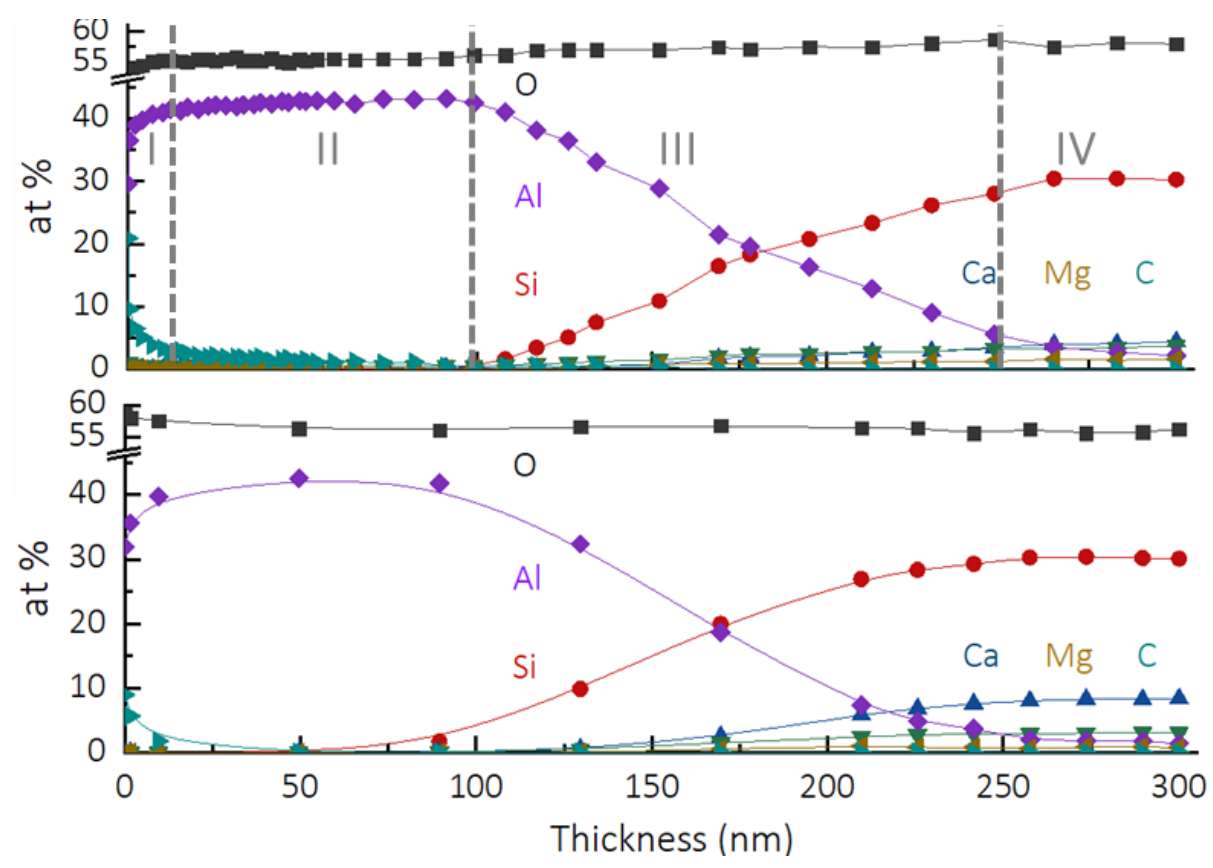

Figure 6. Profiles of atomic fraction of chemical elements $(\mathrm{O}, \mathrm{Si}, \mathrm{Al}, \mathrm{Ca}, \mathrm{Mg}$ and $\mathrm{C})$ through the alumina layer and the structure of the glass. I: surface of the layer; II: layer of Amorphous $\mathrm{Al}_{2} \mathrm{O}_{3}$; III: layer/vial interface and IV: vial. (a) As deposited coating, (b) After hydrothermal ageing.

The concentration profiles for the as processed sample (Figure 6a) can be divided into four parts. At the extreme surface, from 0 to $20 \mathrm{~nm}$ deep, the layer is composed of oxygen, aluminum and carbon, probably due to contamination from exposure to air. Other cations, such as calcium and magnesium from glass are not detected. Between 20 and $100 \mathrm{~nm}$, the atomic fractions of oxygen and aluminum are constant and close to the 60/40 atomic ratio, indicating the presence of a carbon-free alumina layer of constant composition. In this zone of the sample, the carbon content gradually decreases from 3 at\% and it vanishes at ca. $80 \mathrm{~nm}$, where it is no longer detected. In the third region, between 100 and $250 \mathrm{~nm}$, there is a wide interphase between the alumina layer and the glass. In that zone, the molar fraction of aluminum decreases (from 41 to 5\% at.), while that of silicon increases (from 2 to $28 \%$ at.), 
the molar fraction of oxygen being constant. We hypothesize that during the growth of the alumina layer, under the action of heat, the aluminum ions and the silicon ions interdiffuse to form an Al-Si-O aluminosilicate random network of variable composition depending on the probed depth. The apparent thickness of this alumina-silica interphase is $150 \mathrm{~nm}$. However, this value may be biased, due to artefacts from the ionic sputtering of the surface. The molar fractions of $\mathrm{Ca}$ and $\mathrm{Mg}$ slightly increase from the outer to the inner part of this zone, reaching up 3.5 at.\% and 1.2 at.\%, respectively. It is possible that the heat provided to the system during the growth of the alumina is also responsible of the commencement of the diffusion of the alkali or alkaline earth cations through the film. Finally, at depths greater than $270 \mathrm{~nm}$, the mole fractions of each element are constant. This is the core of the glass structure.

A comparable elemental profile is obtained after the autoclave cycle (Figure 6b). Alkali ions from the glass do not diffuse through the layer, which testifies to the barrier performance of the coating system. The atomic fraction of oxygen increases by approaching the surface. It is possible that, at its external part the film contains a non-negligible percentage of hydroxyl groups to form $\mathrm{AlO}_{1+\mathrm{x} / 2}(\mathrm{OH})_{1-\mathrm{x}}($ with $0 \leq \mathrm{x}<1$ ) on the surface formed after the autoclave cycle, which would result to increased oxygen content. The atomic fraction of carbon at the surface is also large (1.8-9 at.\%). Carbon contamination could come from carbonate species deposited on the surface from dissolved $\mathrm{CO}_{2}$ formed during the sterilization cycle. The alumina layer is present at a relatively narrow range, where the atomic fractions of oxygen and aluminum are constant. Carbon is no longer detected at this depth, therefore the film is affected neither by pollution of carbonaceous residues nor a priori by corrosion generated by hydrothermal aging. In addition, the atomic fractions of $\mathrm{Ca}$ and $\mathrm{Mg}$ are zero in this zone, which confirms the barrier performance of the coating. Further away from the surface the interphase between the alumina layer and the glass is still present after the autoclave cycle. The variations in the molar fraction of aluminum (from 41.9 to 1.9 at.\%) and silicon (from 1.7 to $30.2 \%$ at.) are 
comparable to those before sterilization, while the oxygen molar fraction also remains constant. The aluminosilicate interphase shows similar thicknesses before and after the autoclave cycle. Also based on the excellent barrier performance of the very thin films, we conclude that this interdiffusion zone is not altered by the hydrothermal aging. Approaching the core of the glass, the molar fractions of calcium and magnesium gradually increase (up to 8.0 at. $\%$ and 0.6 at. $\%$, respectively). This also shows that the interdiffusion zone first, then the alumina layer afterwards, prevent the migration of elements out of the glass. The identification of an efficient aluminosilicate interfacial barrier is a major finding of the present work; it paves the way towards engineering aluminosilicate coatings with the absence of external, pure alumina layer. In such a configuration, the coating is fulfills its role in preventing the diffusion of the ions from the glass to the content while remaining unaffected from the interaction with the latter during the shelf life of the drug. The produce of such thin coatings is not problematic, by acting essentially on the deposition time. In addition, low deposition times would facilitate the transferability of the CVD process toward industrial production. Further steps towards the validation of aluminosilicate barrier coatings for pharmaceutical applications go beyond the evaluation of the hydrolytic resistance. They would consist in tests with more aggressive, non-neutral solutions, especially basic ones, such as those recommended by the <1660> chapter of the US. Pharmacopeia. [32].

\section{Conclusions}

The amorphous alumina layer uniformly deposited on the inner surface of glass vials by DLICVD exhibits satisfactory barrier performance. The concentrations of extractables obtained from the glass and released into the solution in contact, measured both by titrimetry and ICP, are significantly reduced, in comparison with the uncoated vial. The acidification of the water inside the bottle leads to the partial delamination of the layer weakened by aging in an 
autoclave and results in a significant release of aluminum ions. However, the alkali and alkaline earth cations present in the composition of the glass do not diffuse through the amorphous alumina layer under the applied standardized conditions recommended by the Pharmacopoeia, even after two cycles in the autoclave and successive acidifications. After the release test, for $300 \mathrm{~nm}$ thick alumina films, the composition of the layer is changed on the surface, with the presence of excess oxygen and carbonaceous residues. The concentration of aluminum ions released in solution is particularly high and reveals a probable dissolution of the external part of the alumina film that is partially dissolved to a certain depth. These results are coherent with the previously reported morphology of the hydrolyzed alumina layer, consisting of an external part characterized by a loose and porous structure, and an internal one, adherent to the surface of the glass and characterized by a more compact unaffected structure that still presents good barrier performance.

Finally, for very thin layers of alumina $(<20 \mathrm{~nm})$, the first measurements show low concentrations of extractables, both glass and aluminum ions, significantly lower than those of an uncoated bottle. This is a considerably promising result. The total or partial transformation of the nanometric alumina coating into an interdiffusion layer during alumina growth by DLI-CVD could explain this state of the art performance that deserves to be further consolidated.

\section{Acknowledgements}

The authors are indebted to Jerome Esvan, CIRIMAT, for helping with XPS measurements. SGD Pharma is acknowledged for support.

\section{References}


[1] F. DeGrazio, D. Paskiet, in: Contract Pharma, Rodman Media, 23 January 2012.

[2] R.A. Schaut, W.P. Weeks, PDA J. Pharm. Sci. Technol., 71 (2017) 279-296.

[3] S. Yoneda, T. Torisu, S. Uchiyama, Expert Opin. Drug Delivery, 18 (2021) 459-470.

[4] Anonymous in: EudraLex, Inspections, European Medicines Agency, London, UK, 18 January 2007.

[5] R.G. Iacocca, M. Allgeier, J. Mat. Sci., 42 (2007) 801-811.

[6] R.G. Iacocca, N. Toltl, M. Allgeier, B. Bustard, X. Dong, M. Foubert, J. Hofer, S. Peoples, T. Shelbourn, AAPS PharmSciTech, 11 (2010) 1340-1349.

[7] M. Nocun, D. Burcon, S. Siwulski, Opt. Appl., 38 (2008) 171-179.

[8] D. Ditter, A. Nieto, H.C. Mahler, H. Roehl, M. Wahl, J. Huwyler, A. Allmendinger, J. Pharm. Sci., 107 (2018) 624-637.

[9] P.-L. Etchepare, L. Baggetto, H. Vergnes, D. Samélor, D. Sadowski, B. Caussat, C. Vahlas, Phys. Stat. Sol. C, 12 (2015) 944-952.

[10] P.-L. Etchepare, L. Baggetto, H. Vergnes, D. Samélor, D. Sadowski, B. Caussat, C. Vahlas, Adv. Mater. Interf., 3 (2016) 1600014.

[11] D. Krajišnik, B. Čalija, J. Milić, Mater. Biomed. Eng.: Inorg. Micro- Nanostruct., (2019) 285-327.

[12] S.V. Sotirchos, S.F. Nitodas, Chem. Vap. Dep., 7 (2001) 157-166.

[13] A. Gleizes, C. Vahlas, M.M. Sovar, D. Samélor, M.C. Lafont, Chem. Vap. Dep., 13 (2007) 23-29.

[14] L. Baggetto, C. Charvillat, J. Esvan, Y. Thébault, D. Samélor, H. Vergnes, B. Caussat, A. Gleizes, C. Vahlas, Chem. Vap. Dep., 21 (2015) 343-351.

[15] L. Baggetto, V. Sarou-Kanian, P. Florian, A.N. Gleizes, D. Massiot, C. Vahlas, Phys.Chem.Chem.Phys., 19 (2017) 8101-8110.

[16] P.-L. Etchepare, H. Vergnes, D. Samélor, D. Sadowski, C. Brasme, B. Caussat, C. Vahlas, Adv. Sci. Techn., 91 (2014) 117-122.

[17] M.M. Sovar, D. Samélor, A.N. Gleizes, C. Vahlas, Surf. Coat. Techn., 201 (2007) 91599162.

[18] H. Vergnes, D. Samelor, A. Gleizes, C. Vahlas, B. Caussat, Chem. Vap. Dep., 17 (2011) 181-185.

[19] P.-L. Etchepare, H. Vergnes, D. Samélor, D. Sadowski, B. Caussat, C. Vahlas, Surf. Coat. Technol., 275 (2015) 167-175.

[20] S.M. Lee, D.G. Cahill, T.H. Allen, Phys. Rev. B, 52 (1995) 253-257.

[21] C.o. Europe, Ph. Eur., in: C.o. Europe (Ed.), Counsil of Europe, Strasbourg, 2010, pp. 363-367.

[22] G.H. Fu, J.F. Du, D.H. Pan, O.L. He, J. Non Cryst. Sol., 112 (1989) 454-457.

[23] M. Mizuhashi, G. Gotoh, in, US Patent US4485146A, 1984. 
[24] H. Nagayama, H. Honda, H. Kawahara, J. Electrochem. Soc., 135 (1988) 2013-2016.

[25] J.J. Finley, F.H. Gillery, in: U.S.P.a.T. Office (Ed.) OG USPTO, PPG Industries, Inc., United States, 1998, pp. 11.

[26] M. Klause, U. Rothhaar, M. Bicker, W. Ohling, J. Non Cryst. Sol., 356 (2010) 141-146.

[27] B. Danielzik, M. Heming, J. Segner, M. Spallek, M. Walther, in, US Patent US6200658, 2001.

[28] M. Spallek, M. Walther, M. Lohmeyer, M. Heming, in, US Patent US6537626B1, 2003.

[29] M. Walther, Schott Type I Plus ${ }^{\circledR}$ Containers for Pharmaceutical Packaging, in: H. Bach, D. Krause (Eds.) Thin Films on Glass, Springer-Verlag GmbH Berlin, Heidelberg, 2003, pp. 373-379.

[30] S. Schweiger, C. Neubauer, S.D. Fraser, T. Klein, R. Schennach, A. Reichmann, H. H. Gruber-Woelfler, Surf. Coat. Techn., 258 (2014) 1249-1255.

[31] Y. Balcaen, N. Radutoiu, J. Alexis, J.D. Béguin, L. Lacroix, D. Samelor, C. Vahlas, Surf. Coat. Techn., 206 (2011) 1684-1690.

[32] D. Hunt, General Chapter <1660> Evaluation of the inner surface durability of glass containers. USP-NF, 2012.

Table I. Direct liquid injection and alumina deposition operating conditions

\begin{tabular}{|c|c|c|}
\hline \multirow{5}{*}{ DLI } & Vaporization temperature & $473 \mathrm{~K}\left(200^{\circ} \mathrm{C}\right)$ \\
\hline & Injection frequence & $3 \mathrm{~Hz}$ \\
\hline & Injection time & $3.85 * 10^{-3} \mathrm{~s}$ \\
\hline & Mix $\mathrm{N}_{2}$ flow rate & $300 \mathrm{sccm}$ \\
\hline & Solution flow rate & 0,7 g. $\min ^{-1}$ \\
\hline \multirow{5}{*}{ CVD } & Deposition pressure & $667 \mathrm{~Pa}(5$ Torr $)$ \\
\hline & Set deposition temperature & $753 \mathrm{~K}\left(480^{\circ} \mathrm{C}\right)$ \\
\hline & Dilution gas flow rate & $100 \mathrm{sccm}$ \\
\hline & Total gas flow rate & $587 \mathrm{sccm}$ \\
\hline & $\begin{array}{l}\text { Molar concentration of ATI in the input } \\
\text { gas }\end{array}$ & $1,7.10^{-3}$ \\
\hline
\end{tabular}




\section{Figure captions}

Figure 1. (a): Schematic illustration of the reactor, with the relative positions of the vial and the stainless steel cylinder with regard to the induction coil and the injector nozzle. (b): Experimentally determined temperature at various points in the vial, along its revolution axis and on its internal surface, for a $480{ }^{\circ} \mathrm{C}$ set temperature.

Figure 2. Evolution of the hydrolytic resistance of an alumina coated Type III vial coated with a thin film of alumina, as a function of the estimated mean thickness of the coating. The corresponding maximum volume of such solution; i.e. the minimum hydrolytic resistance of a Type I and the average value for Type III vials are also reported.

Figure 3. SEM cross section micrographs of a films deposited on the internal surface of the vial, (a) as processed, (c) after hydrothermal ageing. Corresponding AFM $2 \times 2 \mu \mathrm{m}^{2}$ maps of (b) as processed, (d) after hydrothermal ageing.

Figure 4. (a) ICP determined concentration of extractables after contact with the inside surface of an uncoated (blue) vial and a coated (cyan) one with a $42 \mathrm{~nm}$ thick alumina film. The last two sets of columns correspond to the total extractables with and without considering $\mathrm{Al}$ ions. (b) Evolution, as a function of the mass of the deposited alumina film, of the concentration of two extractable cations, $\mathrm{Al}$ and $\mathrm{Na}$, representative elements of the coating and the vial, respectively.

Figure 5. Concentrations of extractables from four vials: uncoated, coated with a $383 \mathrm{~nm}$ thick alumina coating after one and after two autoclave cycles, and coated with a $17 \mathrm{~nm}$ thick alumina film after one autoclave cycle. The last two sets of columns correspond to the total extractables with and without considering $\mathrm{Al}$ ions.

Figure 6. Profiles of atomic fraction of chemical elements $(\mathrm{O}, \mathrm{Si}, \mathrm{Al}, \mathrm{Ca}, \mathrm{Mg}$ and $\mathrm{C})$ through the alumina layer and the structure of the glass. I: surface of the layer; II: layer of Amorphous 
Surface and Coatings Technology, 2021, 425, 127711

$\mathrm{Al}_{2} \mathrm{O}_{3}$; III: layer/vial interface and IV: vial. (a) As deposited coating, (b) After hydrothermal ageing. 


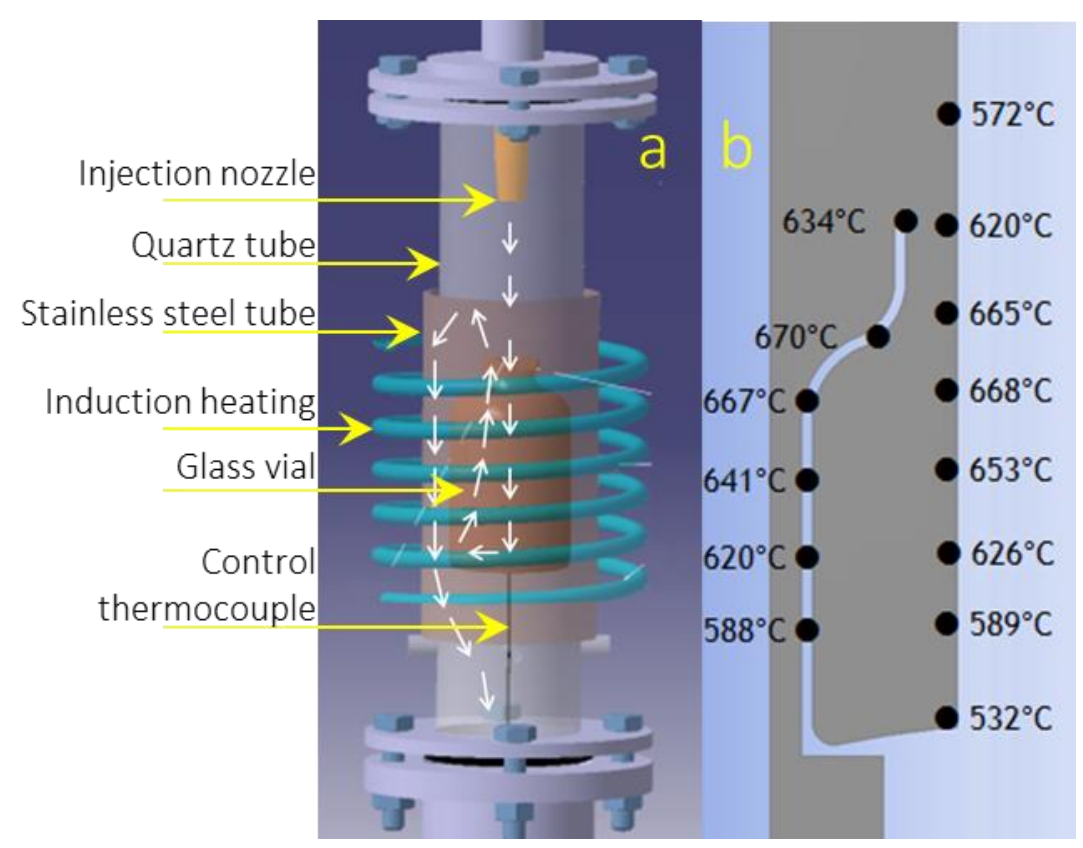

1. 


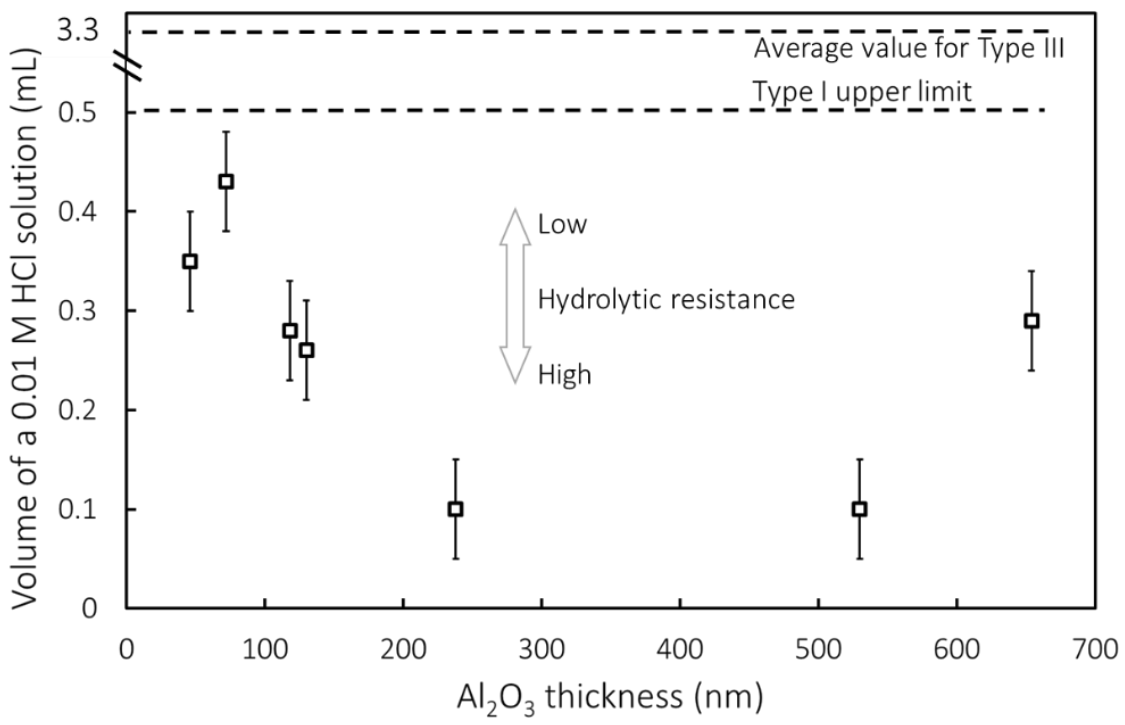

2. 

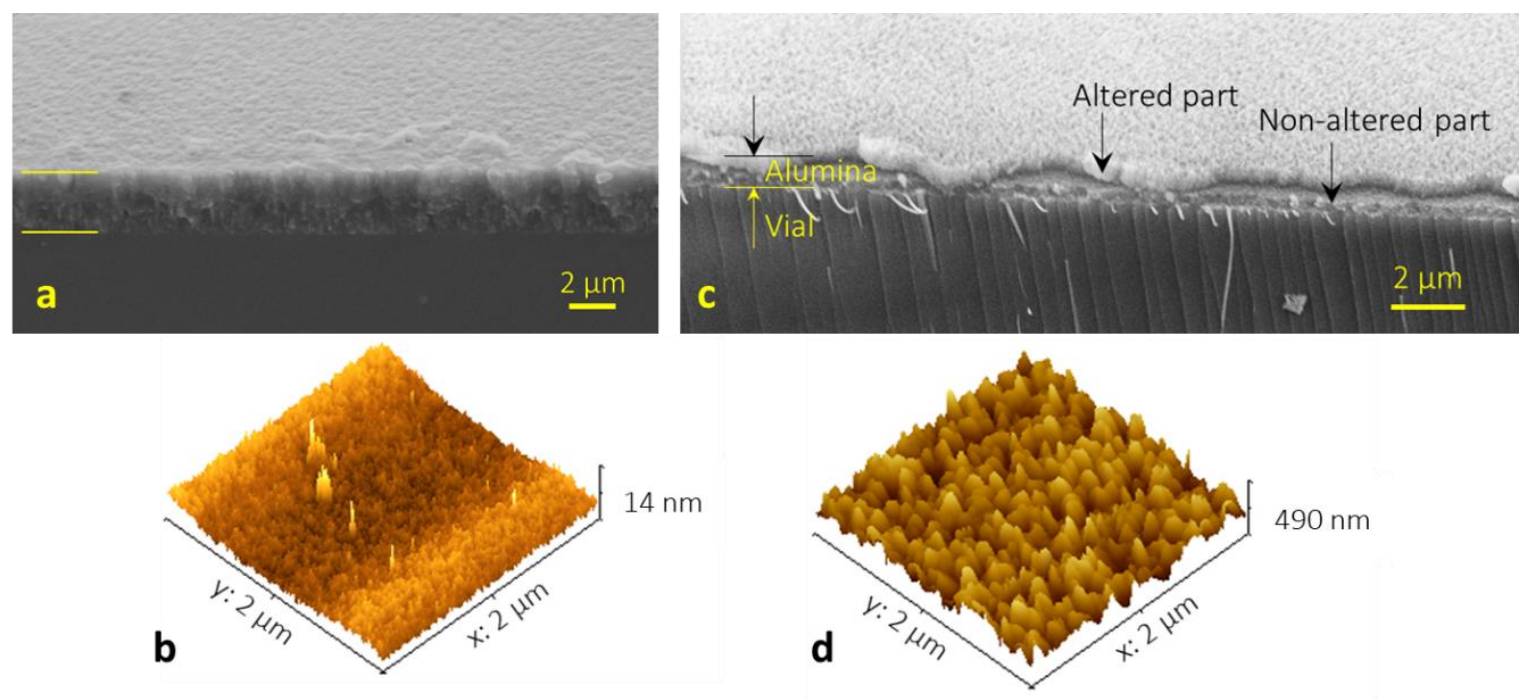

3. 

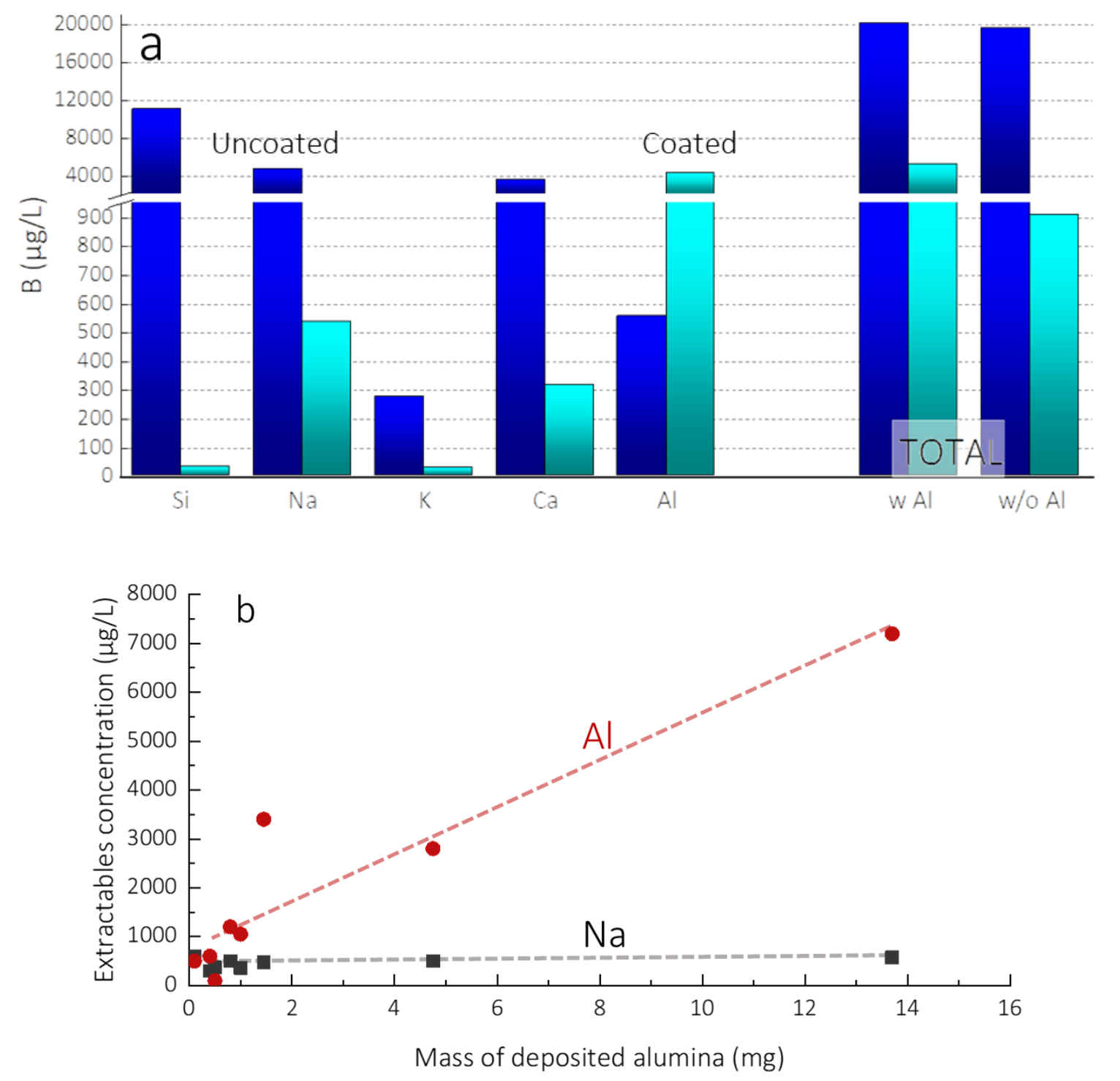

4. 


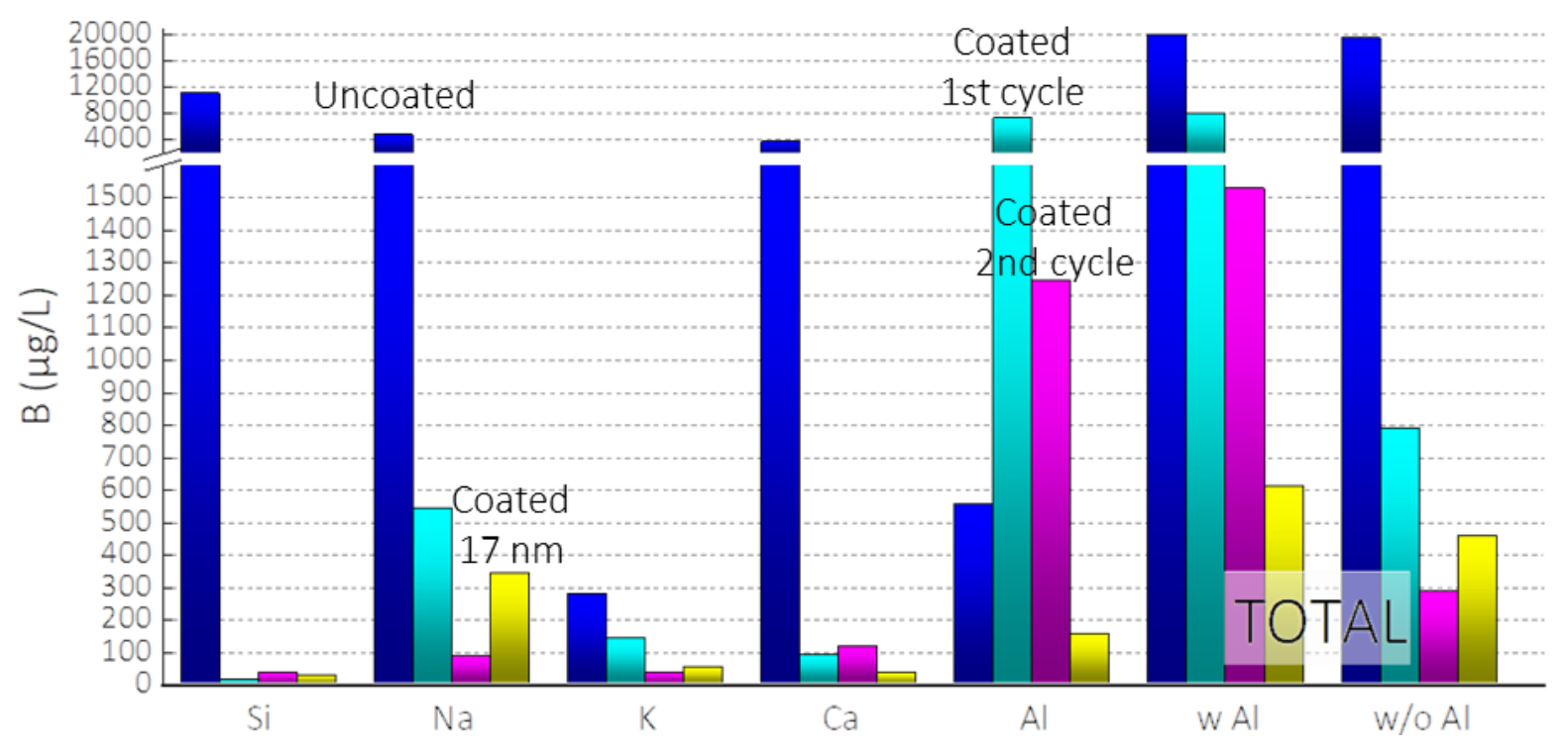

5. 


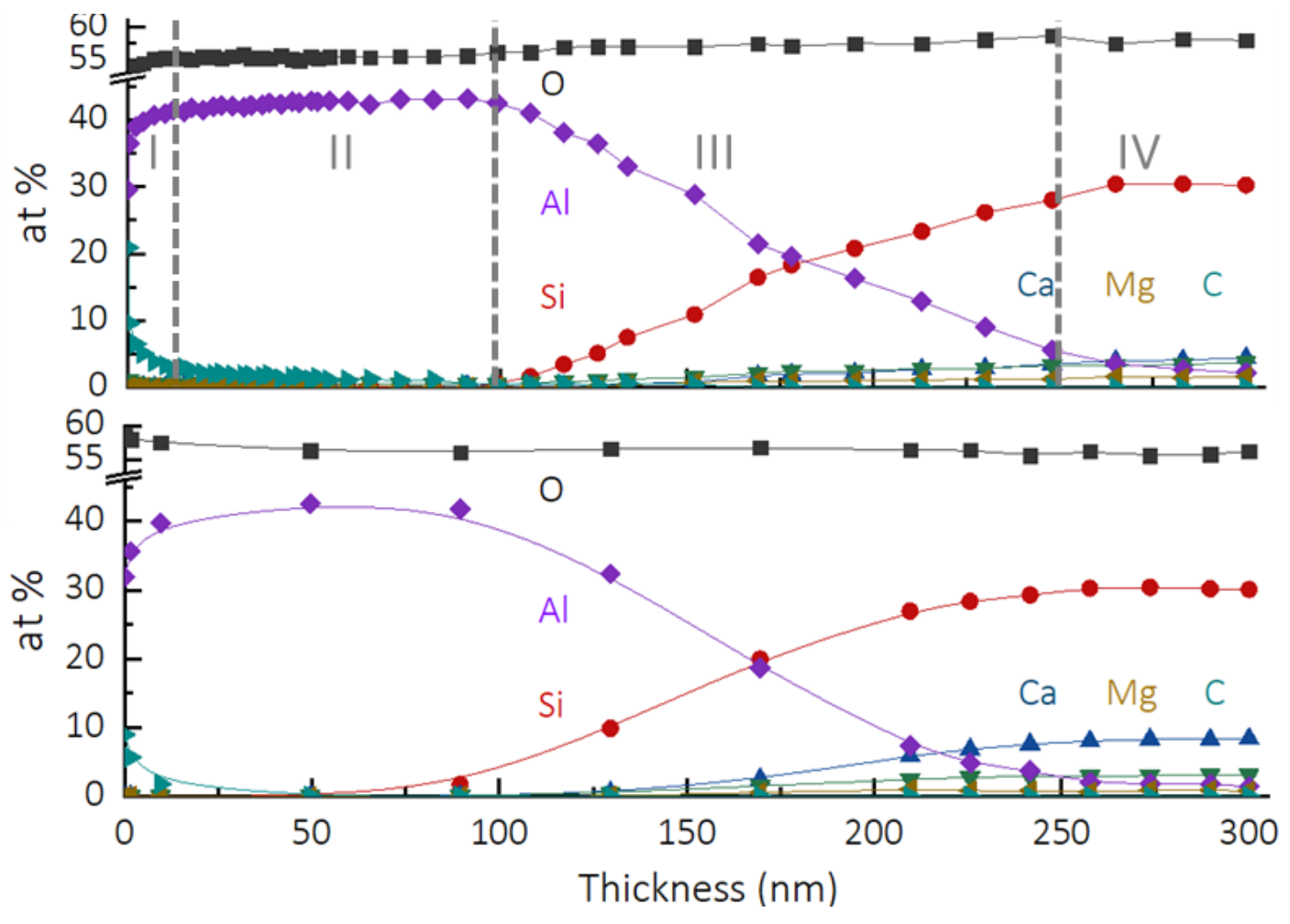

6. 